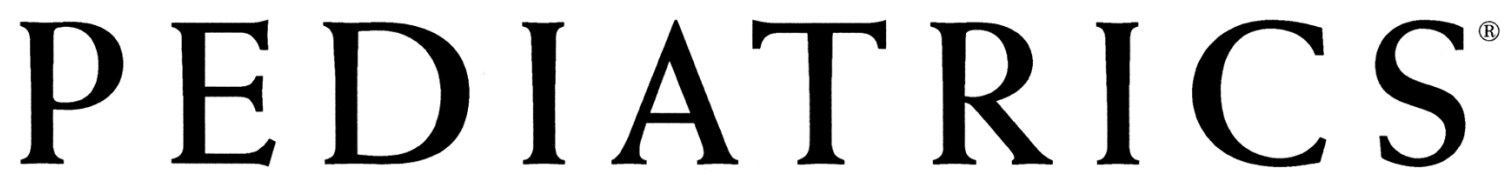

OFFICIAL JOURNAL OF THE AMERICAN ACADEMY OF PEDIATRICS

\title{
Pentavalent Rotavirus Vaccine and Prevention of Gastroenteritis Hospitalizations in Australia
}

Emma J. Field, Hassan Vally, Keith Grimwood and Stephen B. Lambert Pediatrics 2010;126; 506; originally published online August 23, 2010; DOI: $10.1542 /$ peds.2010-0443

The online version of this article, along with updated information and services, is located on the World Wide Web at: http://pediatrics.aappublications.org/content/126/3/e506.full.html

PEDIATRICS is the official journal of the American Academy of Pediatrics. A monthly publication, it has been published continuously since 1948. PEDIATRICS is owned, published, and trademarked by the American Academy of Pediatrics, 141 Northwest Point Boulevard, Elk Grove Village, Illinois, 60007. Copyright (c) 2010 by the American Academy of Pediatrics. All rights reserved. Print ISSN: 0031-4005. Online ISSN: 1098-4275.

\section{American Academy of Pediatrics}




\section{Pentavalent Rotavirus Vaccine and Prevention of Gastroenteritis Hospitalizations in Australia}

WHAT'S KNOWN ON THIS SUBJECT: There are limited developed country post-introduction effectiveness data for RV5 outside the US.

WHAT THIS STUDY ADDS: With high three-dose coverage, RV5 was effective in preventing RV and non-RV AGE hospitalizations in vaccinated children and older, unvaccinated age-groups in Queensland, Australia.

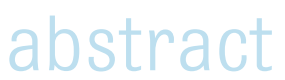

OBJECTIVE: A publicly funded, universal infant pentavalent rotavirus vaccine (RV5) program was implemented in Queensland, Australia, in mid-2007. We sought to assess vaccine effectiveness (VE) of 3 doses of RV5 at preventing rotavirus and nonrotavirus acute gastroenteritis (AGE) hospitalizations in the first birth cohort and impact on hospitalizations in all age groups.

METHODS: Hospitalization rates for rotavirus and nonrotavirus AGE in all age groups before and after RV5 introduction were compared. Population vaccine coverage, hospitalization data, and individual vaccination status were obtained from routinely collected, publicly funded state- and nationally based data sets. Data linkage was performed to calculate 3-dose VE for preventing hospitalization in the eligible age group.

RESULTS: RV5 coverage in the first eligible birth cohort was $89.6 \%$ for at least 1 dose and $73.1 \%$ for 3 doses. Three-dose VE for preventing nonrotavirus AGE hospitalization was $62.3 \%$ to $63.9 \%$ (any/primary diagnosis) and $89.3 \%$ to $93.9 \%$ (any/primary diagnosis) for rotavirus hospitalizations. After program implementation, there were immediate and sustained reductions in rotavirus hospitalizations for those who were younger than 20 years and nonrotavirus AGE-coded hospitalizations for those who were younger than 5 years.

CONCLUSIONS: RV5 is highly effective at preventing rotavirus hospitalizations in a developed country setting, confirming efficacy figures from the pivotal clinical trial. Additional direct and indirect effects are substantial and include reductions in nonrotavirus AGE hospitalizations in vaccinated age groups and rotavirus and nonrotavirus AGE hospitalization rates in older age groups. Pediatrics 2010;126: e506-e512
AUTHORS: Emma J. Field, MPH \& TM, MAppEpid, a,b Hassan Vally, PhD, MAppEpid, ${ }^{\mathrm{b}}$ Keith Grimwood, MD, ${ }^{\mathrm{c}}$ and Stephen B. Lambert, MBBS, PhD ${ }^{\mathrm{c}, \mathrm{d}}$

${ }^{a}$ Communicable Diseases Branch, Queensland Health, Brisbane, Queensland, Australia; ${ }^{b}$ National Centre for Epidemiology and Population Health, College of Medicine, Biology and Environment, Australian National University, Canberra, Australian Capital Territory, Australia; ${ }^{c}$ Queensland Paediatric Infectious Diseases Laboratory, Queensland Children's Medical Research Institute, University of Queensland, Royal Children's Hospital, Herston, Queensland, Australia; and ${ }^{d}$ Clinical Medical Virology Centre, Sir Albert Sakzewski Virus Research Centre, University of Queensland, St Lucia, Queensland, Australia

KEY WORDS

rotavirus, pentavalent rotavirus vaccine, vaccine effectiveness, screening method

\section{ABBREVIATIONS}

AGE-acute gastroenteritis

RV5 - pentavalent rotavirus vaccine

RV1-monovalent rotavirus vaccine

VE-vaccine effectiveness

$\mathrm{Cl}$-confidence interval

ED-emergency department

QHAPDC—Queensland Hospital Admitted Patient Data Collection ICD-10-AM — International Classification of Diseases, Tenth Revision, Australian Modification

VIVAS - Vaccine Information and Vaccine Administration System ACIR-Australian Childhood Immunisation Register

PPV—-proportion of the population vaccinated

www.pediatrics.org/cgi/doi/10.1542/peds.2010-0443

doi:10.1542/peds.2010-0443

Accepted for publication Jun 1, 2010

Address correspondence to Stephen B. Lambert, MBBS, PhD, Queensland Paediatric Infectious Diseases Laboratory, Queensland Children's Medical Research Institute, Royal Children's Hospital, Herston Road, Herston 4029 Queensland, Australia. E-mail: sblambert@uq.edu.au

PEDIATRICS (ISSN Numbers: Print, 0031-4005; Online, 1098-4275)

Copyright $@ 2010$ by the American Academy of Pediatrics

FINANGIAL DISCLOSURE: Dr Grimwood has been a member of a Rotavirus Advisory Board and received support for conference attendance, lecture fees, and a research grant from GlaxoSmithKline and has also received a research grant from Merck; Dr Lambert has been a co-investigator of vaccine trials and epidemiologic studies sponsored by Merck, CSL Ltd, and GlaxoSmithKline and has received support for conference attendance from GlaxoSmithKline and CSL Ltd; Ms Field and Dr Vally have no financial relationships relevant to this article to disclose. 
Rotavirus is the leading cause of severe acute gastroenteritis (AGE) in early childhood, globally causing $>500000$ deaths and 2.4 million hospital admissions each year for children who are younger than 5 years. ${ }^{1}$ To combat this disease burden, 2 live oral rotavirus vaccines, RotaTeq (pentavalent rotavirus vaccine [RV5; Merck Vaccines, Whitehouse Station, NJ]) and Rotarix (monovalent rotavirus vaccine [RV1; GlaxoSmithKline Biologicals, Rixensart, Belgium]), have been developed and shown to be highly efficacious against severe rotavirus disease, including hospitalization (85\%-98\%), in large clinical trials. ${ }^{2,3}$

Since the introduction of RV5, several studies have reported on its postlicensure use and impact in real-world settings. In the United States, RV5 was introduced in 2006; by 2008, with modest 1-dose coverage of $31 \%$ in children who were younger than 2 years, the onset and peak of the 2007-2008 rotavirus season were delayed by 15 and 8 weeks, respectively, and the proportion of fecal specimens that were positive for rotavirus was reduced by $69 \% .{ }^{4}$ This decline in rotavirus activity persisted into the 2008-2009 season. ${ }^{5}$

A single-center case-control study that was conducted in Houston, Texas, and used a control group that combined children who had rotavirus-negative AGE or acute respiratory infection yielded a 3-dose vaccine effectiveness (VE) of $88 \%$ (95\% confidence interval [CI]: 68\%-96\%) against rotavirus-AGE that required hospitalization or emergency department (ED) visits. ${ }^{6} \mathrm{~A}$ nationwide health insurance claimbased, postlicensure study that compared concurrent cohorts of children who received 3 doses of RV 5 with those who received 3 doses of diphtheria-tetanus-acellular pertussis and no doses of RV5 provided a VE for preventing ED presentations and hospitalizations as a result of rotavirus and all-cause AGE of $100 \%$ (95\% Cl: $87 \%-100 \%)$ and $59 \% \quad(95 \% \quad \mathrm{Cl}$ : $47 \%-68 \%)$, respectively ${ }^{7}$; however, the performance of RV5 seems to be setting dependent. A case-control study in Nicaragua, a high-burden, developing country where 1-dose RV5 coverage quickly reached $80 \%,{ }^{8}$ demonstrated a 3-dose effectiveness of just $46 \%$ (95\% Cl: $18 \%-64 \%)$ at preventing hospitalization or intravenous rehydration. ${ }^{9}$ Early evidence from double-blind, randomized, multicenter, placebocontrolled phase III trials in other developing countries supports this concept, with efficacy of 3 doses of RV5 of 64\% (95\% Cl: 40\%-79\%) and 51\% (95\% $\mathrm{Cl}$ : $13 \%-73 \%)$ against severe rotavirus gastroenteritis in Africa and Asia, respectively..$^{10}$ The scope for rotavirus vaccines to prevent ǵlobal diarrhearelated deaths in children was demonstrated in Mexico, where RV1 was introduced in February 2006, reaching 1-dose coverage of at least $74 \%$ for children who were aged $\leq 11$ months by December 2007. ${ }^{11}$ When comparing median values for 2003 to 2006 with 2008 data, the diarrhea-related mortality rate was reduced by $41 \%(95 \% \mathrm{Cl}$ : $36 \%-47 \%)$ for children who were aged $\leq 11$ months and by $29 \%$ ( $95 \% \mathrm{Cl}: 17 \%-$ $39 \%)$ for those who were aged between 12 and 23 months. ${ }^{11}$ The primary aim of this study was to calculate the VE of RV5 at preventing hospitalization in the first annual birth cohort of eligible children in the high 3-dose coverage setting of Queensland, Australia.

\section{METHODS}

The state of Queensland, Australia, has a population of 4.4 million people and a current annual birth cohort of $63000 .{ }^{12}$ Rotavirus vaccine was added to the Australian universal, publicly funded immunization program for all infants who were born on or after May 1, 2007, with children in a given state or territory offered a full course of either RV1 or RV5. ${ }^{13}$ In Queensland, this program commenced on July 1, 2007, with RV5.

\section{Hospital Admission Data}

The Queensland Hospital Admitted Patient Data Collection (QHAPDC) collects admission data from all public and private hospitals in Queensland. ${ }^{14}$ Records from 2000 to 2008 with International Classification of Diseases, Tenth Revision, Australian Modification (ICD-10-AM) codes for AGE including rotavirus (ICD-10-AM codes A00A09 excluding A02.2, A06.4-A06.8, and K52) ${ }^{15,16}$ in the primary or any secondary diagnostic field were extracted from QHAPDC in October 2009. Age group-specific rates of hospitalization in the prevaccine era (mean annual rates for 2000-2006) were compared with 2007 and 2008 figures by calculating rate ratios with $95 \% \mathrm{Cls}$ by using Stata 10 (Stata Corp, College Station, TX).

\section{Vaccination Status of Hospitalized Children}

The Vaccine Information and Vaccine Administration System (VIVAS) is the vaccination register and management system that records all vaccines that are administered in Queensland. VIVAS records only vaccines that are administered; it is not a population-based register and does not have records for individuals who receive no vaccines. VIVAS vaccination data are provided to the national, population-based Australian Childhood Immunization Register (ACIR).

RV5 vaccination records for hospitalized children were extracted from VIVAS for the period of July 1, 2007, to December 31, 2008. Rotavirus vaccinations were considered valid when administered $\geq 14$ days before rotavirus hospitalization. For this project, children with RV5 vaccination records markedly outside standard practice (receipt of rotavirus vaccine at $\leq 4$ 
weeks or $\geq 52$ weeks of age or interval between doses of $\leq 7$ days) were validated by telephone contact with the vaccine service provider.

\section{Population Vaccine Coverage}

ACIR captures immunization data from children who are younger than 7 years and enrolled in the Australian universal health insurance scheme, Medicare. This is essentially a complete population register with $99 \%$ of the annual national birth cohort registered with Medicare by 1 year of age. Children who are not enrolled in Medicare can be added to the ACIR via a supplementary number. ${ }^{17}$ The National Centre for Immunisation Research and Surveillance of Vaccine Preventable Diseases provided population rotavirus vaccine coverage proportions, including children who had received no vaccine doses, from the ACIR for children who were born between May 1, 2007, and April 30, 2008. ACIR coverage figures for 3-dose, primarycourse vaccines are typically calculated by using the "third-dose assumption": if a child has a record of receiving dose 3 in a series, then they are assumed to have received doses 1 and 2 and therefore to be fully vaccinated for the primary course of that vaccine, even if there is no record for dose 1 or 2 having been administered. ${ }^{18,19}$ For this analysis, coverage data used were as reported and were not modified by using the third-dose assumption.

\section{Data Linkage and VE}

Data linkage was performed in Microsoft Excel (Microsoft Corp, Redmond, WA). Data from multiple instances of the same individual within VIVAS and QHAPDC were collapsed to a single record, and records in both data sets were linked by using a created key that consists of surname and date of birth. Linkage was validated by using the given name. Minor spelling and other variations in the given name field (involving 1-letter differences, addition of the second given name to the first given name field, or addition of a hyphen in first given names with 2 words) were manually reviewed and accepted as valid linkages when surname and date of birth matched.

VE was calculated by using the screening method, comparing the proportion of cases vaccinated and the proportion of the population vaccinated (PPV), ${ }^{20}$ with exact $95 \%$ Cls for proportions ${ }^{21,22}$. $\mathrm{VE}=\left(1-\left(\frac{\mathrm{PCV}}{1-\mathrm{PCV}} \times \frac{1-\mathrm{PPV}}{\mathrm{PPV}}\right)\right)$

$\times 100$

A case was defined as any child who was born between May 1, 2007, and April 30, 2008, and had a QHAPDC record of hospital admission with a rotavirus or nonrotavirus AGE ICD10-AM code in any field. The minimum age of analysis for eligible children was 35 weeks to allow for 3 -dose vaccine administration (latest age for third dose delivery: 33 weeks) ${ }^{23}$ and development of a protective immune response (2 weeks). ${ }^{2}$ This criterion may have excluded some children for whom 3 doses of RV5 were delivered early, but given the structure and timing of routine primary course vaccinations in Australia, this number is likely to be exceedingly small. For the purposes of VE calculation, the unit of comparison was the child rather than the hospital admission. This means that children who had multiple admissions for AGE during the study period were included in the analysis data set once. The VE for RV5 at preventing hospitalization was calculated for the period from January 1, 2008 (6 months after program commencement), to December 31 , 2008, in the first 12-month birth cohort of children eligible for publicly funded vaccination.

\section{Ethics and Confidential Data} Approvals

Ethical approval for this study was granted by Queensland Children's Health Services and the Australian National University Human Research Ethics Committees. Approval for access to confidential data held by Queensland Health was granted by the Director General of Queensland Health.

\section{RESULTS}

\section{Hospital Admission Data}

We extracted 257061 hospital records with an AGE ICD-10-AM code (including rotavirus) as the primary or any secondary diagnosis with an admission date between January 1, 2000, and December 31, 2008, from QHAPDC. Records for which the usual residence was outside Queensland (7674) or not specified (130) were removed, leaving 249257 records for additional analysis.

There was an immediate reduction in rotavirus hospital admissions for individuals who were younger than 20 years after vaccine introduction in July 2007, a finding sustained in 2008 (Table 1, Fig 1). There were also reductions in nonrotavirus AGE for children who were aged 1 to 4 years in 2007 and for all children who were younger than 5 years in 2008 (Table 1, Fig 1). Hospitalization rates increased in older age groups for both rotavirus and nonrotavirus AGE in 2007 and 2008, with significantly higher rate ratios for rotavirus hospitalization in those who were aged $\geq 45$ years in 2007 and those who were aged $\geq 65$ years in 2008; however, these rate increases represented only minor changes in the absolute number of rotavirus hospitalizations. For the 45- to 64-yearolds, the mean annual count of hospitalizations from 2000 to 2006 was 3 , increasing to 13 in 2007 and 4 in 2008. During the same period, the number of rotavirus hospitalizations 
TABLE 1 Annual Rotavirus and Nonrotavirus AGE Hospital Admission Rates by Age Group in 20002008

\begin{tabular}{|c|c|c|c|c|c|}
\hline \multirow[t]{2}{*}{ Age Group } & \multirow{2}{*}{$\begin{array}{c}\text { Mean Annual } \\
2000 \text { to } 2006, \\
\text { Rate }(100000 / y)\end{array}$} & \multicolumn{2}{|c|}{2007} & \multicolumn{2}{|c|}{2008} \\
\hline & & $\begin{array}{c}\text { Rate } \\
(100000 / y)\end{array}$ & $\begin{array}{l}\text { Rate Ratio } \\
(95 \% \mathrm{Cl})\end{array}$ & $\begin{array}{c}\text { Rate } \\
(100000 / y)\end{array}$ & $\begin{array}{l}\text { Rate Ratio } \\
(95 \% \mathrm{Cl})\end{array}$ \\
\hline \multicolumn{6}{|c|}{$\begin{array}{l}\text { Rotavirus hospitalizations (ICD } \\
\text { code A08.0, any field) }\end{array}$} \\
\hline$<1$ & 374.6 & 203.6 & $0.5(0.4-0.7)$ & 124.0 & $0.3(0.3-0.4)$ \\
\hline 1 & 479.9 & 243.1 & $0.5(0.4-0.6)$ & 220.4 & $0.5(0.4-0.5)$ \\
\hline 2 & 272.2 & 128.5 & $0.5(0.4-0.6)$ & 163.4 & $0.6(0.5-0.7)$ \\
\hline 3 & 142.8 & 60.9 & $0.4(0.3-0.6)$ & 47.9 & $0.3(0.3-0.5)$ \\
\hline 4 & 76.4 & 33.5 & $0.4(0.3-0.7)$ & 50.8 & $0.7(0.5-1.0)$ \\
\hline $0-4$ & 149.2 & 135.7 & $0.5(0.5-0.6)$ & 122.4 & $0.5(0.4-0.5)$ \\
\hline $5-19$ & 7.9 & 3.1 & $0.4(0.3-0.6)$ & 3.3 & $0.4(0.3-0.6)$ \\
\hline $20-44$ & 0.3 & 0.5 & $1.7(0.8-3.6)$ & 0.3 & $1.0(0.4-2.6)$ \\
\hline $45-64$ & 0.3 & 1.2 & $3.8(1.9-7.5)$ & 0.4 & $1.1(0.4-3.3)$ \\
\hline$\geq 65$ & 1.7 & 6.7 & $4.0(2.6-6.1)$ & 4.4 & $2.6(1.5-4.2)$ \\
\hline \multicolumn{6}{|c|}{$\begin{array}{l}\text { Nonrotavirus AGE hospitalizations } \\
\quad \text { (ICD codes A00-A09, K52 } \\
\quad \text { excludes A02.2, A06.4-A06.8, } \\
\text { A08.0, any field) }\end{array}$} \\
\hline$<1$ & 1687.7 & 1625.6 & $1.0(0.9-1.0)$ & 1230.2 & $0.7(0.7-0.8)$ \\
\hline 1 & 1945.6 & 1531.1 & $0.8(0.7-0.8)$ & 1074.6 & $0.6(0.5-0.6)$ \\
\hline 2 & 1260.9 & 892.4 & $0.7(0.6-0.8)$ & 702.2 & $0.6(0.5-0.6)$ \\
\hline 3 & 785.7 & 579.9 & $0.7(0.7-0.8)$ & 434.2 & $0.6(0.5-0.6)$ \\
\hline 4 & 550.9 & 403.9 & $0.7(0.6-0.8)$ & 322.7 & $0.6(0.5-0.7)$ \\
\hline $0-4$ & 1239.4 & 1017.6 & $0.8(0.8-0.9)$ & 763.0 & $0.6(0.6-0.6)$ \\
\hline $5-19$ & 192.6 & 183.5 & $1.0(0.9-1.0)$ & 183.9 & $1.0(0.9-1.0)$ \\
\hline $20-44$ & 262.0 & 272.0 & $1.0(1.0-1.1)$ & 285.9 & $1.1(1.1-1.1)$ \\
\hline $45-64$ & 290.9 & 313.7 & $1.1(1.0-1.1)$ & 324.2 & $1.1(1.1-1.2)$ \\
\hline$\geq 65$ & 665.5 & 837.8 & $1.3(1.2-1.3)$ & 792.1 & $1.2(1.2-1.2)$ \\
\hline
\end{tabular}

for those who were aged $\geq 65$ years increased from an annual mean number of 8 (2000-2006) to 34 and 23 for 2007 and 2008, respectively.

\section{Vaccination Data}

ACIR coverage figures for the first 12month cohort of Queensland children who were eligible for RV5 vaccination and born between May 1, 2007, and April 30, 2008 (61 617) at 12 months of age were $73.1 \%$ (45 048) for 3 doses, $12.9 \%$ (7902) for 2 doses only, $3.6 \%$ (2243) for 1 dose only, and 10.4\% (6424) for no doses (B. Hull, MPH, personal written communication, November 23, 2009). For 3-dose VE calculations, partially vaccinated children were removed from PPV coverage estimates. ${ }^{20}$

\section{Data Linkage and VE}

There were 35 and 488 hospital admissions for rotavirus and nonrotavirus AGE (any diagnosis) from 34 and 425 ary 1, 2008, and December 31, 2008, from the first birth cohort of children who were eligible for RV5 vaccination (date of birth from May 1, 2007, to April 30, 2008). Of the children who were hospitalized for rotavirus, 16 (46\%) had no rotavirus vaccination record $\geq 14$ days before hospitalization, 4 (12\%) had received 1 dose of RV5, 2 (6\%) had received 2 doses, and 12 (35\%) had received 3 doses. Of the children who were hospitalized for nonrotavirus AGE, 96 (23\%) had no rotavirus vaccination record $\geq 14$ days before hospitalization, 21 (5\%) had received 1 dose of RV5, 54 (13\%) had received 2 doses, and 254 (58\%) had received 3 doses. For 3-dose VE estimates, hospitalizations for 6 and 75 partially vaccinated children were excluded, leaving 28 rotavirus and 350 nonrotavirus AGE hospitalizations for calculations of children, respectively, between Janu- proportion of cases vaccinated, respectively (Table 2). The 3-dose VE for preventing any hospitalization was high for both rotavirus and nonrotavirus AGE as primary or any diagnosis (Table 2).

\section{DISCUSSION}

This study demonstrates the very high VE (89.3\%-93.9\%) of 3-dose RV5 at preventing rotavirus hospitalization in a high-coverage, developed country setting. Furthermore, 3-dose RV5 was highly effective $(62.2 \%-63.9 \%)$ at preventing nonrotavirus AGE hospitalizations in the first annual birth cohort for which vaccine was used in Queensland. Our ecological findings show the substantial indirect effects of this vaccine in nonvaccinated age groups for both rotavirus and nonrotavirus AGE hospitalizations. We found immediate and sustained reductions in rates of rotavirus hospitalization of all patients who were younger than 20 years and nonrotavirus AGE hospitalization of children who were younger than 5 years.

It is interesting that we identified marked increases in rotavirus hospitalization rates in older age groups in 2007 and 2008, with minimal increments in nonrotavirus AGE hospitalizations. These findings are most likely attributable to changes in laboratory testing behavior rather than real changes in severe disease incidence. We previously showed that there have been dramatic increases in rotavirus testing in Queensland public hospitals in older age groups, with a $307 \%$ and $184 \%$ increase in 2007 and 2008, respectively, for those aged $\geq 65$ years compared with the mean number of annual tests between 2000 and 2006. ${ }^{24}$ This rise in testing may be attributable to increased awareness of the morbidity and mortality that are associated with gastroenteritis in the institu- 


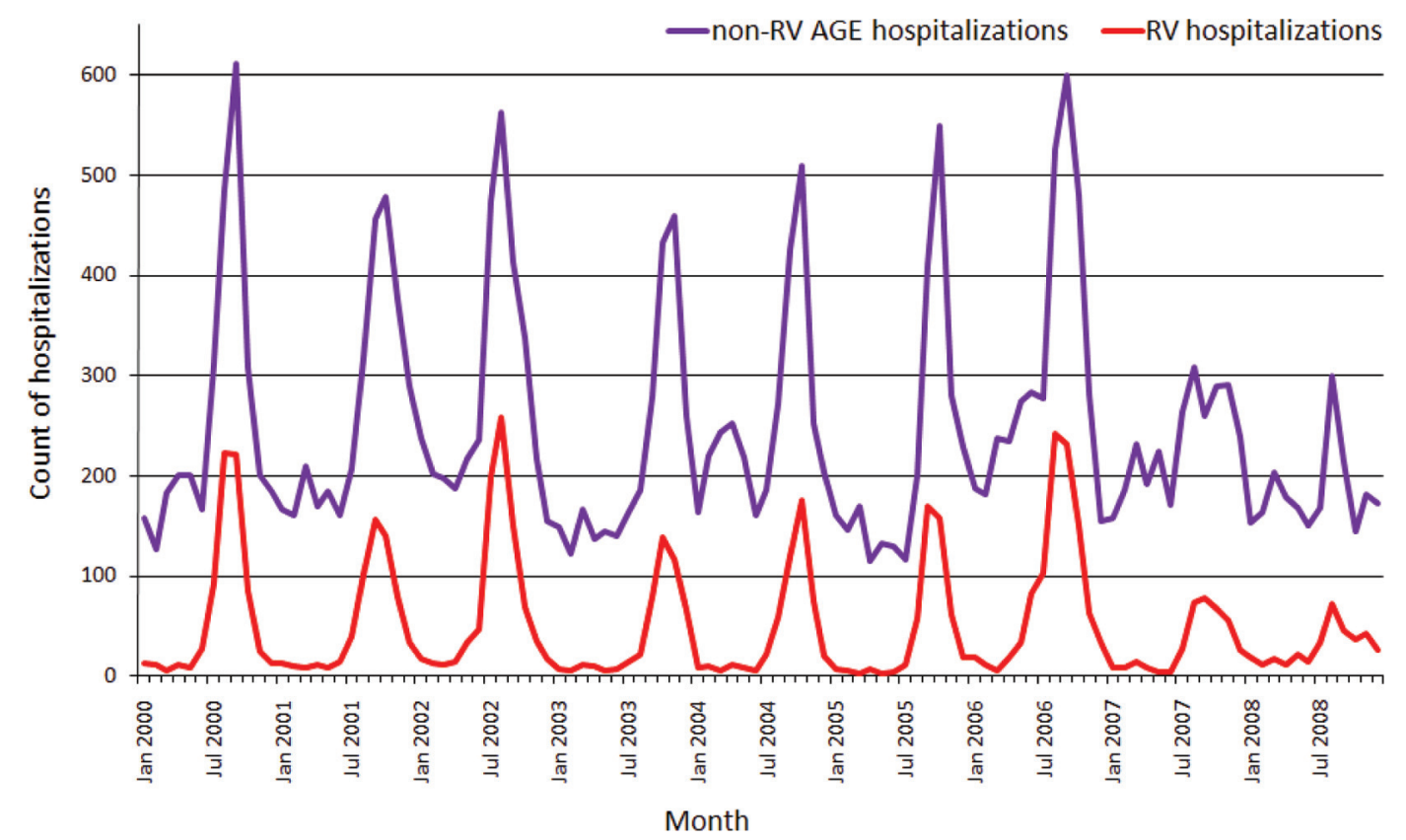

FIGURE 1

Frequency of rotavirus and nonrotavirus AGE hospitalizations by month for children who were younger than 5 years, Queensland, 2000 to 2008.

TABLE 2 Rotavirus and Nonrotavirus AGE Hospitalizations, Case and Population Vaccination Status, and 3-Dose VE for Preventing Hospitalization

\begin{tabular}{|c|c|c|c|c|c|c|c|}
\hline \multirow[t]{2}{*}{ Hospitalization Diagnoses } & \multicolumn{2}{|c|}{ Case Vaccination Status } & \multirow[t]{2}{*}{ PCV } & \multicolumn{2}{|c|}{ Population Vaccination Status } & \multirow[t]{2}{*}{ PPV } & \multirow[t]{2}{*}{ VE \% $(95 \% \mathrm{Cl})$} \\
\hline & $\begin{array}{c}\text { Fully } \\
\text { Vaccinated }\end{array}$ & Unvaccinated & & $\begin{array}{c}\text { Fully } \\
\text { Vaccinated }\end{array}$ & Unvaccinated & & \\
\hline Nonrotavirus AGE ICD code in any field & 254 & 96 & 0.726 & 45048 & 6424 & 0.875 & $62.2(51.8-70.3)$ \\
\hline Nonrotavirus AGE ICD code as primary diagnosis & 195 & 77 & 0.717 & 45048 & 6424 & 0.875 & $63.9(52.4-72.4)$ \\
\hline Rotavirus ICD code in any field & 12 & 16 & 0.429 & 45048 & 6424 & 0.875 & $89.3(75.9-95.4)$ \\
\hline Rotavirus ICD code as primary diagnosis & 6 & 14 & 0.300 & 45048 & 6424 & 0.875 & $93.9(83.1-98.1)$ \\
\hline
\end{tabular}

PCV indicates proportion of cases vaccinated.

tionalized elderly and modified laboratory testing behavior. ${ }^{24}$ Regardless, the increase in testing was associated with a $52 \%$ and $23 \%$ reduction in proportion of tested specimens that were rotavirus positive in 2007 and 2008, respectively, coinciding with RV5 introduction. ${ }^{24}$

As with all observational methods, bias and other issues need to be considered when interpreting our findings. ${ }^{25}$ Because the screening method compares the proportion of 2 groups vaccinated rather than rates in different exposure categories, we presented only 3 -dose VE. If a vaccine requires multiple doses and is effective, then the distribution of dose coverage in the population (noncases), compared with cases, will show that more children have complete rather than partial coverage. Because our 3-dose coverage was very high, VE values for at least 1 dose (any dose) or at least 2 doses were dominated by children who had received 3 doses, making VE estimates very similar to the 3-dose only VE (data not shown).

The PPV value used in VE calculations in this study was not the result of a limited sampling exercise, and the key data sets-ACIR and QHAPDCare routinely collected and population based. Queensland children's vaccination records are provided to ACIR from VIVAS, and the validity of ACIR data has been assessed previously. The most likely ACIR inaccu- racy is for PPV to be underestimated, ${ }^{17,18}$ which would result in an underestimation of VE, meaning that our VE estimates may be conservative. We previously demonstrated that rotavirus coding for public hospital admissions is highly specific for rotavirus disease. Between 2001 and 2006, of 222 children who were younger than 5 years and had rotavirus-coded hospitalizations, 197 (98\%) of 201 with rotavirus testing available were laboratory confirmed..$^{15}$ There was no systematic change in hospital coding in the period covered by this study. Given the narrow age range of the children in the effectiveness component of this analysis-a 12-month birth cohort-we did not 
control for any potential confounding as a result of age.

In other settings, rotavirus-specific ICD coding has been shown repeatedly to be an insensitive means of measuring rotavirus hospitalization burden in children. ${ }^{26,27}$ In Australia, between 1993 and 2002, rotavirus-specific ICD coding identified 4260 hospitalizations per year of children who were younger than 5 years, ${ }^{28}$ whereas a method that estimated admissions by using linked hospitalization and laboratory testing data between 1998 and 2003 gave an estimate of 9970 in the same age group. ${ }^{16}$ In Queensland, between 2000 and 2006, of 1383 nonrotavirus AGE-coded hospitalizations of children who were younger than 5 years, 113 (26\%) of 428 for whom rotavirus testing was performed were laboratory confirmed. ${ }^{15}$ This misclassification is confirmed by the solid 3-dose VE for RV5 preventing nonrotavirus AGE hospital admissions of $63.9 \%$, and this impact can be further observed in the sudden blunting of nonrotavirus AGE admissions during rotavirus season (Fig 1).

Our findings around nonrotavirus AGE are similar to the VE values reported for a complete 3-dose course of the

\section{REFERENCES}

1. Grimwood K, Lambert SB. Rotavirus vaccines: opportunities and challenges. Hum Vaccin. 2009;5(2):57-69

2. Vesikari T, Matson D0, Dennehy $P$, et al. Safety and efficacy of a pentavalent humanbovine (WC3) reassortant rotavirus vaccine. N Engl J Med. 2006;354(1):23-33

3. Ruiz-Palacios GM, Perez-Schael I, Velazquez FR, et al. Safety and efficacy of an attenuated vaccine against severe rotavirus gastroenteritis. N Engl J Med. 2006;354(1): 11-22

4. Tate JE, Panozzo CA, Payne DC, et al. Decline and change in seasonality of US rotavirus activity after the introduction of rotavirus vaccine. Pediatrics. 2009; $124(2): 465-471$

5. Centers for Disease Control and Prevention. now-withdrawn RotaShield vaccine (Wyeth Lederle Vaccines, Philadelphia, PA): $83 \%$ for preventing all-cause gastroenteritis hospital admissions and $43 \%$ for all-cause gastroenteritis ED visits during a 1-year follow-up period. ${ }^{29}$ In effect, our findings also represent a population-wide vaccine probe study, suggesting that misclassification of hospitalizations as a result of rotavirus by using incorrect or less specific AGE codes is common.

Indirect vaccine effects are seen in older age groups with reductions in rates of rotavirus and nonrotavirus AGE admissions in unvaccinated children and adolescents. This coincides with immediate reductions in the proportion of laboratory tests that were positive for rotavirus in all age groups after RV5 introduction. ${ }^{24}$ In our setting, a prompt decrease in rotavirus transmission is likely to have occurred after the very rapid 1-dose (89.6\%) and 3-dose (73.1\%) coverage seen in the first 12-month birth cohort. The timing of Queensland's rotavirus season may also have been of benefit, with at least 2 months of publicly funded vaccination occurring in 2007 before the traditional peak rotavirus month of September. ${ }^{24}$ Similar to 7 -valent proteinpolysaccharide conjugate pneumococ-

Reduction in rotavirus after vaccine introduction-United States, 2000-2009. MMWR Morb Mortal Wkly Rep. 2009;58(41): 1146-1149

6. Boom JA, Tate JE, Sahni LC, et al. Effectiveness of pentavalent rotavirus vaccine in a large urban population in the United States. Pediatrics. 2010;125(2). Available at: www.pediatrics.org/cgi/content/full/125/ 2/e199

7. Wang FT, Mast TC, Glass RJ, Loughlin J, Seeger JD. Effectiveness of the pentavalent rotavirus vaccine in preventing gastroenteritis in the United States. Pediatrics. 2010; 125(2). Available at: www.pediatrics.org/ cgi/content/full/125/2/e208

8. Orozco M, Vasquez J, Pedreira C, et al. Uptake of rotavirus vaccine and national cal vaccine, ${ }^{30,31}$ these indirect effects were unable to be calculated in infant efficacy studies, and additional documentation of such benefits in other populations is required.

\section{CONCLUSIONS}

There is now a small but increasing collection of studies that show postlicensure effectiveness or ecological changes in rotavirus activity after RV5 introduction. ${ }^{4-8,24,32}$ Our findings confirm these and provide ecological evidence of reductions in hospitalization rates in older, unvaccinated children and adolescents for rotavirus and nonrotavirus AGE. Additional postimplementation research is required to identify means to improve 3 -dose coverage and to understand better the effectiveness variations in the various settings where RV 5 is currently used. ${ }^{33}$ Our findings should encourage consideration of vaccine use in similar industrialized countries. ${ }^{34}$

\section{ACKNOWLEDGMENTS}

This project was undertaken when Ms Field was a Masters of Applied Epidemiology (MAE) scholar. The MAE program is funded by the Australian Commonwealth Department of Health and Ageing.

trends of acute gastroenteritis among children in Nicaragua. J Infect Dis. 2009; 200 (suppl 1):S125-S130

9. Patel M, Pedreira C, De Oliveira LH, et al. Association between pentavalent rotavirus vaccine and severe rotavirus diarrhea among children in Nicaragua. JAMA. 2009; 301 (21):2243-2251

10. Rotavirus vaccines: an update. Wkly Epidemiol Rec. 2009;84(50):533-537

11. Richardson V, Hernandez-Pichardo J, Quintanar-Solares M, et al. Effect of rotavirus vaccination on death from childhood diarrhea in Mexico. N Engl J Med. 2010;362 (4):299-305

12. Australian Bureau of Statistics. 3301.0 - Births, Australia, 2008. Available at: www. abs.gov.au/ausstats/abs@.nsf/Products/ 
E02CF7437F4ED5A9CA25766A00120F67? opendocument. Accessed May 29, 2010

13. Macartney KK, Burgess MA. Rapid impact of rotavirus vaccination in the United States: implications for Australia. Med J Aust. 2009; 191(3):131-132

14. Queensland Health. 2009-2010 Queensland hospital admitted patient data collection (QHAPDC): manual of instructions and procedures for the reporting of QHAPDC data. Available at: www.health.qld.gov.au/hic/ manuals/09-10QHAPDC/MANUAL0910.pdf. Accessed May 29, 2010

15. Campbell SJ, Nissen MD, Lambert SB. Rotavirus epidemiology in Queensland during the pre-vaccine era. Commun Dis Intell. 2009;33 (2):204-208

16. Galati JC, Harsley S, Richmond P, Carlin JB. The burden of rotavirus-related illness among young children on the Australian health care system. Aust N Z J Public Health. 2006;30(5):416-421

17. Hull BP, Deeks SL, McIntyre PB. The Australian Childhood Immunisation Register: a model for universal immunisation registers? Vaccine. 2009;27 (37):5054-5060

18. Hull BP, Lawrence GL, MacIntyre CR, Mclntyre PB. Immunisation coverage in Australia corrected for under-reporting to the Australian Childhood Immunisation Register. Aust N Z J Public Health. 2003;27 (5):533-538

19. Hull BP, Lawrence GL, MacIntyre CR, Mclntyre PB. Estimating immunisation coverage: is the 'third dose assumption' still valid? Commun Dis Intell. 2003;27(3):357-361
20. Farrington CP. Estimation of vaccine effectiveness using the screening method. Int $J$ Epidemiol. 1993;22(4):742-746

21. Andrews RM, Counahan ML, Hogg GG, Mclntyre PB. Effectiveness of a publicly funded pneumococcal vaccination program against invasive pneumococcal disease among the elderly in Victoria, Australia. Vaccine. 2004;23(2):132-138

22. Armitage P, Matthews JN, Berry G. Statistical Methods in Medical Research. 4th ed. Malden, MA: Blackwell Science; 2002

23. National Health and Medical Research Council. The Australian Immunisation Handbook. 9th ed. Canberra, Australia: Australian Government Publishing Service; 2008

24. Lambert SB, Faux CE, Hall L, et al. Early evidence for direct and indirect effects of the infant rotavirus vaccine program in Queensland. Med J Aust. 2009;191(3): 157-160

25. Torvaldsen S, Mclntyre PB. Observational methods in epidemiologic assessment of vaccine effectiveness. Commun Dis Intell. 2002;26(3):451-457

26. Hsu VP, Staat MA, Roberts N, et al. Use of active surveillance to validate International Classification of Diseases code estimates of rotavirus hospitalizations in children. Pediatrics. 2005;115(1):78-82

27. Mast TC, Walter EB, Bulotsky M, et al. Burden of childhood rotavirus disease on health systems in the United States. Pediatr Infect Dis J. 2010;29(2):e19-e25

28. Newall AT, Maclntyre R, Wang H, Hull B,
Macartney K. Burden of severe rotavirus disease in Australia. J Paediatr Child Health. 2006;42 (9):521-527

29. Tate JE, Curns AT, Cortese MM, et al. Burden of acute gastroenteritis hospitalizations and emergency department visits in US children that is potentially preventable by rotavirus vaccination: a probe study using the now-withdrawn RotaShield vaccine. Pediatrics. 2009;123(3):744-749

30. Whitney CG, Farley MM, Hadler J, et al. Decline in invasive pneumococcal disease after the introduction of proteinpolysaccharide conjugate vaccine. N Engl J Med. 2003;348(18):1737-1746

31. Pilishvili T, Lexau C, Farley MM, et al. Sustained reductions in invasive pneumococcal disease in the era of conjugate vaccine. $J$ Infect Dis. 2010;201(1):32-41

32. Clark HF, Lawley D, Mallette LA, DiNubile MJ, Hodinka RL. Decline in cases of rotavirus gastroenteritis presenting to the Children's Hospital of Philadelphia after introduction of a pentavalent rotavirus vaccine. Clin Vaccine Immunol. 2009;16(3):382-386

33. Patel MM, Parashar UD. Assessing the effectiveness and public health impact of rotavirus vaccines after introduction in immunization programs. J Infect Dis. 2009; 200(suppl 1):S291-S299

34. Milne R, Grimwood K. Should rotavirus vaccines be included in the national immunization program of a small developed country? Expert Rev Pharmacoecon Outcomes Res. 2009;9(5):401-404 


\section{Pentavalent Rotavirus Vaccine and Prevention of Gastroenteritis Hospitalizations in Australia}

Emma J. Field, Hassan Vally, Keith Grimwood and Stephen B. Lambert

Pediatrics 2010;126; e506; originally published online August 23, 2010; DOI: $10.1542 /$ peds. 2010-0443

\section{Updated Information \& Services}

\section{References}

Citations

Subspecialty Collections

Permissions \& Licensing

Reprints including high resolution figures, can be found at: http://pediatrics.aappublications.org/content/126/3/e506.full.h tml

This article cites 28 articles, 7 of which can be accessed free at:

http://pediatrics.aappublications.org/content/126/3/e506.full.h tml\#ref-list-1

This article has been cited by 4 HighWire-hosted articles: http://pediatrics.aappublications.org/content/126/3/e506.full.h tml\#related-urls

This article, along with others on similar topics, appears in the following collection(s):

Allergy \& Dermatology

http://pediatrics.aappublications.org/cgi/collection/allergy_an d_dermatology

Information about reproducing this article in parts (figures, tables) or in its entirety can be found online at:

http://pediatrics.aappublications.org/site/misc/Permissions.xht $\mathrm{ml}$

Information about ordering reprints can be found online: http://pediatrics.aappublications.org/site/misc/reprints.xhtml

PEDIATRICS is the official journal of the American Academy of Pediatrics. A monthly publication, it has been published continuously since 1948. PEDIATRICS is owned, published, and trademarked by the American Academy of Pediatrics, 141 Northwest Point Boulevard, Elk Grove Village, Illinois, 60007. Copyright @ 2010 by the American Academy of Pediatrics. All rights reserved. Print ISSN: 0031-4005. Online ISSN: 1098-4275.

\section{American Academy of Pediatrics}

DEDICATED TO THE HEALTH OF ALL CHILDREN ${ }^{\mathrm{m}}$ 